\title{
El Rock Radical Vasco. La constitución de los sujetos políticos a través de la música
}

\author{
Basque Radical Rock. Constituting the political subjects \\ through the music
}

Gorka Roman Etxebarrieta • gorka.roman@ehu.eus

UPV-EHU. ESCUELA DE MAGISTERIO DE LEIOA.

DEPARTAMENTO DE DIDÁCTICA DE LA LENGUA Y LA LITERATURA

Recibido: 31/10/2017

Aceptado: 16/05/2018

\section{Resumen}

El Rock Radical Vasco ha ejercido una influencia notable sobre la juventud vasca a lo largo de las últimas décadas. Éste habría posibilitado el surgimiento de nuevos movimientos sociales que habrían ejercido un gran impacto sociocultural pero también político en el seno de la sociedad vasca. Hablaríamos de un tipo de génesis de nuevas identidades culturales y políticas, protagonizada en su mayoría por jóvenes insatisfechos con las estructuras político-económicas hegemónicas, que encontrarían en la música un elemento de expresión, de unión y de acción colectiva. El Rock Radical Vasco representó durante décadas la antítesis a un modelo social, económico y cultural tradicional que tildó al recién nacido movimiento musical de modelo sociocultural transgresor y altamente peligroso. No obstante, la influencia del Rock Radical Vasco ha perdurado hasta nuestros días y ha posibilitado el surgimiento y supervivencia de una serie de identidades políticas y culturales que han marcado profundamente la estructura y funcionamiento de la arena vasca de lo social.

El presente artículo trata de decodificar de un modo teórico y etnográfico, así como recopilando los testimonios de los propios protagonistas, el significado y simbolismo que se encuentra tras este emergente movimiento musical y político a la vez, en constante expansión durante las décadas de los 80 y 90, además de analizar la influencia que ejerció en la arena de lo social y cultural del País Vasco.

Palabras clave: Rock Radical Vasco, música y política, contracultura, nacionalismo, violencia.

\section{Abstract}

The «Rock Radical Vasco» or Basque Radical Rock has had a deep and transcendental influence and impact over the Basque youth in the last three decades. It has directly or indirectly made possible the birth of some new movements of great social and political relevance. These aforementioned movements have been in general leaded by young peers ready to confront the existing hegemonic sociopolitical powers. The «Rock Radical Vasco» organized for long years a fierce resistance against the political, judicial and police structures that tried by all means to criminalize and illegalize what they considered to be a transgressor and highly dangerous movement against their own status quo.

The present paper tries to decode some of the key elements behind the emergence and spreading of this musical but also political movement, that so deeply influenced the youth of the time, overstepping the ideological boundaries and limits of the Basque Country. Likewise, we will analyze the transcendental role performed by the Punk movement within the «Rock Radical Vasco.

Different sources and experts had been consulted when writing the present theoretical paper to tackle in the most objective manner this yet polemic topic. We will also consider as reference sources some of the most prestigious voices in the field, some of them also being part of the very same process or movement.

Key words: Basque Radical Rock, political identity, nationalism, counter culture, violence. 


\section{INTRODUCCIÓN}

El Rock Radical Vasco ha ejercido una influencia innegable y trascendental sobre la juventud vasca a lo largo de las últimas décadas. Ha sido el responsable directa o indirectamente del surgimiento de nuevos movimientos sociales con una repercusión sociocultural y política indiscutible, protagonizados en su mayoría por jóvenes insatisfechos con las estructuras político-económicas dominantes. El Rock Radical Vasco articuló durante años un duro pulso frente a las fuerzas e instancias hegemónicas (políticas, judiciales y policiales) que intentaron por todos los medios criminalizar e ilegalizar lo que consideraban un movimiento sociocultural transgresor y altamente peligroso para sus propios intereses.

En el presente artículo se intentarán descifrar algunas de las claves para comprender el porqué y el como del surgimiento de este movimiento musical pero político a la vez, que influenció a jóvenes capaces de trascender las fronteras geográficas e ideológicas del País Vasco. Del mismo modo, analizaremos el rol fundamental desempeñado por el movimiento punk en el seno del Rock Radical Vasco.

Observaremos cuales fueron los orígenes socioculturales, políticos y estilísticos del movimiento, remontándonos hasta las reivindicativas décadas de los setenta y ochenta en una Inglaterra en pleno proceso de desindustrialización que marginaba a los jóvenes punks y otras contraculturas no clasificables dentro de los parámetros morales impuestos por las fuerzas políticas conservadoras del momento. También se intentará analizar el devenir y evolución de este fenómeno cultural surgido en una esfera local (el Reino Unido), que posteriormente se globalizaría y exportaría al resto del planeta, para volver a relocalizarse adoptando una serie de características sociopolíticas y culturales de cada una de las sociedades de acogida.

Para el desarrollo de este artículo acudiremos a una serie de fuentes que nos den una idea «real» de lo que sucedió y de cómo sucedió. Tomaremos como referencia textos de autores de diversa procedencia, ya que las perspectivas, voces y testimonios surgidos desde el interior del propio fenómeno y las aportaciones teóricas propuestas por expertos externos y de diversas nacionalidades, se complementan a la perfección y se enriquecen mutuamente.

\section{CUESTIONES SOBRE EL MARCO TEÓRICO Y EL MARCO METODOLÓGICO}

Como ya adelantábamos anteriormente, el presente artículo aborda el objeto de estudios, el rock radical vasco y sus diversas manifestaciones socioculturales y políticas, desde una perspectiva metodológica esencialmente descriptiva. También se hace hincapié en cuestiones de carácter histórico, subrayando la importancia de los elementes tanto sincrónicos como diacrónicos, ya que es de este modo que entenderemos el origen y devenir de los 
procesos sociopolíticos y culturales que nos ocupan de un modo global. No debemos olvidar tampoco el carácter etnográfico del artículo, ya que parte del entramado que lo sustenta ha sido construido a partir de relatos e historias contadas en primera persona.

Este artículo se nutre de fuentes y campos tan variados como la historia, la etnografía, la ciencia política o la antropología social y cultural, y es por esta razón que podríamos considerar el presente trabajo como un texto descriptivo de tipo multidisciplinar. Los objetivos del mismo son meramente descriptivos y es por ello que no se presentan como tales, sino que se trabajan de un modo transversal a lo largo del texto. Del mismo modo, no se pretende defender una hipótesis específica, sino que se intenta articular una narración de tipo antropológico e histórico que nos acerque al objeto de estudio desde una perspectiva teórica pero etnográfica a la vez.

\section{LOS ORÍGENES DEL PUNK}

La década de los setenta fue sin lugar a dudas un periodo convulso y desolador en muchos sentidos, pero sobre todo lo fue para los jóvenes. La alta tasa de desempleo, las estrictas normas morales impuestas por las clases dominantes y una sensación de frustración generalizada originaron la chispa que revolucionaría el panorama sociocultural juvenil de la época. Una nueva contracultura se haría hueco a "gritos» y subvertiría las estructuras socioculturales tradicionales a base de música estridente, estilismos transgresores y una puesta en escena agresiva que se negaría a asumir los roles conservadores establecidos. El Punk había nacido y lo había hecho surgiendo casi espontáneamente de los empobrecidos, marginados y oscuros suburbios industrializados. En palabras de Jakue Pascual (1987: 42), el Punk no pretende modificar el sistema, lo niega porque este no ofrece otra cosa que la integración sin condiciones. El movimiento punk por lo tanto, se convertiría conscientemente en lo antagónico, lo antitético, y consecuentemente las rígidas estructuras sociales y políticas del momento lo verían como algo peligroso que habría de combatirse en pos de la defensa del Status Quo. Así, canciones como «God Save the Queen» o "Anarchy in the UK» de The Sex Pistols, serían consideradas por las esferas dominantes como aberraciones moralmente impuras que supondrían un ataque directo contra su sociedad "perfecta».

Fue de los suburbios londinenses de donde surgió el grito "roto» e inconformista que se sublevaría contra el orden establecido y contra el conservadurismo imperante en el seno de la sociedad inglesa. Lo convencional sería atacado sin piedad y el nuevo movimiento trasgresor adquiriría relevancia en el panorama musical y cultural británico. Esta nueva contracultura, iconoclasta al extremo y de carácter local, pronto se apoderaría de las calles londinenses ${ }^{1}$. Sin embargo, su carácter altamente «contagioso» y «performativo» haría que

\footnotetext{
${ }^{1}$ El barrio londinense de Camden Town continúa siendo en el presente el lugar donde más visibles son las coloridas crestas y los llamativos estilos punkis. Decenas de tiendas asociadas a esta contracultura llenan las calles del famoso mercado, y miles de clientes acuden a diario a adquirir productos asociados al movimiento Punk.
} 
el fenómeno en un principio de tipo local, pronto saltara a una escena global extendiéndose rápidamente por Europa, el continente americano e incluso Asia. Cada cultura adoptaría posteriormente este fenómeno global y lo readaptaría y contextualizaría en su propia cultura local, como es el caso de los primeros grupos punk pioneros del denominado Rock Radical Vasco ${ }^{2}$.

El punk surge en palabras de Hebdige (1979) de una corriente estética procedente de la clase obrera que adopta como símbolos las «cadenas» y la «suciedad», y que pretende oponerse a la opulencia representada por las estrellas del Rock del momento cada vez más elitistas como Bowie o Lou Reed. Jakue Pascual (1947: 42) afirma que el punk es además «la negación del hippy», otro movimiento cultural globalizado y de gran auge hasta aquel momento. El movimiento punk se caracterizaría en gran medida por su oposición y negación al resto de movimientos musicales, culturales y políticos.

Al igual que el reggae, el punk se caracterizó por una oposición total a los valores hegemónicos y opresores de la sociedad tradicional británica de la época. Hebdige (1979: 42) afirma que el punk podría considerarse en parte, como una adaptación o traducción blanca de la etnicidad negra. El reggae británico aportó al punk el carácter de crítica política que a éste le faltaba. En ocasiones y sobre todo en lugares donde ciertas tendencias xenofóbicas representadas principalmente por el National Front (Frente Nacional) eran obvias, los punks se organizaron y lucharon para acabar con éstas. Grupos como The Clash y The Slits utilizaron material tomado del movimiento reggae y en ocasiones lo convirtieron en eslóganes propios. Sin embargo, las profundas diferencias entre ambos movimientos musicales y culturales eran obvias. El punk era básicamente un tipo de música de carácter local producido por y para jóvenes británicos blancos. Mientras que los jóvenes negros del Reino Unido creaban un tipo de música que les remitía mediante un profundo y sofisticado sistema simbólico a lugares imaginados por la comunidad como es el caso de África, los punkis se encontraban atrapados en un oscuro y sórdido presente supeditado a una opresora y retrógrada Gran Bretaña. El problema se solucionó eliminando la necesidad de evasión a lugares «imaginados» para constituir un espacio local que se caracterizaría por la «negatividad» (Hebdige, 1979).

De esta primera reflexión deberíamos destacar la relevancia y protagonismo del concepto contracultura ya que es este el que nos aporta una sólida base teórica y conceptual para comprender, describir y analizar el fenómeno punk y lo que este supuso en tanto en cuanto a su difusión, influencia sociocultural y política, y una posterior metamorfosis en otro tipo de movimientos sociales, culturales y políticos, como es el rock radical vasco.

\footnotetext{
2 Algunos de estos grupos de música punk mostraban su total desacuerdo con la utilización de este término para referirse a ellos. Eskorbuto fue una de las bandas que más duramente arremetió contra la definición de Rock Radical Vasco.
} 
En este sentido podemos afirmar que la contracultura es un paradigma que nos permite comprender el devenir de expresiones culturales alternativas a un sistema. «Incluye manifestaciones artísticas, científicas, sociales, filosóficas, económicas y políticas, contrarias o diferentes a la Cultura Oficial, a la cultura del sistema; es una forma específica de ver la realidad, establece límites a lo hegemónico, formula interrogantes, introduce enigmas en el imaginario social» (Herrera 2009: 73).

\section{DEL PUNK INGLÉS AL ROCK RADICAL VASCO}

Como ya hemos mencionado anteriormente, el movimiento punk surgió de los suburbios londinenses de la década de los setenta en un contexto caracterizado por unos acuciantes niveles de desempleo causados en parte por el proceso de desindustrialización que vivió la Gran Bretaña de la época. Las estructuras socio-ideológicas y culturales también estaban en pleno declive debido en parte a la delicada situación de la economía nacional. Y es en este contexto de depresión laboral y de opresión política e ideológica conservadora donde surge el movimiento punk como alternativa transgresora a una sociedad anclada en el pasado y excluyente para muchos jóvenes. Si bien en un principio éste fue un fenómeno de carácter local, pronto se extendería al resto del planeta convirtiéndose en una corriente cultural y musical globalizada. Grupos como The Clash o The Sex Pistols con el controvertido Sid Vicious a la cabeza, comenzarían a sonar en los equipos de música y emisoras de radio de un gran número de países europeos y americanos. El estilismo punk pronto comenzó a imitarse y mimetizarse en estas sociedades. Las crestas de colores, las cadenas, los imperdibles y las chupas de cuero pintadas pasaron de las calles de Covent Garden y Camden Town, a Paris, Madrid, Bilbao o Sestao. Un nuevo movimiento musical y cultural transgresor y globalizado se estaba visibilizando en las calles de miles de ciudades y pueblos de todo el mundo.

La nueva contracultura formaría parte de un flujo transnacional que no atendería a límites locales y que tomaría fuerza en el seno de aquellas sociedades víctimas de los mismos males endémicos de la sociedad británica; desempleo, desilusión, marginación...

De este proceso surge en palabras de Ion Andoni del Amo (2016), una influencia que proviene del País Vasco francés y que conllevará una ruptura generacional y geográfica más marcada en zonas obreras y que cala entre unos jóvenes que rompen con todo lo anterior, reivindicando una nueva forma de protesta más irreverente disconforme con la política y sociedad que los rodea.

Sin embargo, el movimiento punk tendería a adoptar las especificidades sociales y culturales del contexto local. Como cabría esperar, las manifestaciones e identidades de la contracultura punk se hibridizaron fusionando lo local y global del movimiento. Lo híbrido en palabras de Robert Young (1995), iguala lo diferente y diferencia lo igual. Hablamos en definitiva de una nueva identidad, movimiento o concepto que surge de la fusión de varios 
elementos que no volverán a ser los mismos. Hebdige (1979) señala que incluso en el caso del movimiento punk inicial, se dieron una serie de fusiones híbridas como la creada por The Clash entre reggae y punk, que derivaría en el «punk-dub».

La situación social, cultural, política y sobre todo económica del País Vasco era similar a la de otros lugares de Europa y Gran Bretaña donde el movimiento punk irrumpió con fuerza para oponerse y hacer frente a las clases sociales y políticas dominantes. Es necesario no obstante comprender que este fenómeno sociocultural y político importado desde el extranjero, hubo de ser adaptado a la idiosincrasia específica del País Vasco que ya dolía de una serie de problemáticas ligadas a la complicada situación política del país. «Para entender el fenómeno en el País Vasco, debemos tener presente una serie de coordenadas propias: la inserción de este fenómeno en la cultura vasca y la manifestación de una identidad nacional en crisis de definición, por parte de un sector importante de la juventud vasca» (Dávila y Amezaga, 2003: 222).

Además, miles de jóvenes vascos que sufrían altas tasas de desempleo o que fueron víctimas de la marginación y de la estigmatización social, tuvieron que hacer frente a otro fenómeno no tan cotidiano en el seno del resto de sociedades europeas; hablamos de la represión política impuesta por el Estado Español postfranquista. «La represión, el paro producido por la desindustrialización o la droga - muestras de una situación social crítica- constituyeron el contexto en el que se desarrolló el movimiento conocido como Rock Radical Vasco» (Del Amo, 2016: 241).

Como ya hemos mencionado anteriormente, la contracultura punk se había globalizado para después reinsertarse en nuevos contextos locales con sus propias características y peculiaridades idiosincráticas. En el caso vasco las reivindicaciones sociales y culturales se fusionarían con demandas de carácter político, a pesar de que en un principio este hecho no fue tan obvio. Si bien las relaciones iniciales entre el movimiento punk y la Izquierda Abertzale $^{3}$ no fueron muy fluidas, con el tiempo muchos de los obstáculos que los distanciaban fueron superándose. No obstante, en sus comienzos algunos grupos punk se revelaron contra ciertas etiquetas políticas como recuerda Jakue Pascual (1987: 45); «El término Rock Radical Vasco es un término polémico, pero útil para hacernos una idea del fenómeno, ya que grupos como Eskorbuto arremeten contra estas siglas por considerarlas instrumentalizadoras».

Dávila y Amezaga (2003: 222) también inciden en este aspecto cuando afirman que «existen problemas en la definición del rock radical, en cuanto que muchos de los grupos que participaron en ese movimiento musical no comparten la opinión de esta etiqueta y lo que ello conllevaba: una cierta vinculación con las organizaciones nacionalistas radicales».

\footnotetext{
${ }^{3}$ Movimiento político, social y cultural independentista vasco de ideología socialista y marxista. Tradicionalmente ha estado representado por Herri Batasuna, Batasuna, Euskal Herritarrok o Bildu en el presente.
} 
Otros grupos como Hetzainak o Zikatriz también mostraron su rechazo a ser englobados dentro de una determinada ideología política. Espinosa y López (1993: 100) recogieron algunos de los testimonios de los líderes de una serie de bandas punk vascas como el del cantante de Zikatriz quien afirmó que «todo es un montaje para conseguir los votos de los jóvenes punks... Les comenté que todo me parecía un truco, y que para mí el rock ni votaba, ni tenía ideología política. También les recordé que al principio nos llamaban vascos frustrados porque fumábamos porros y ahora dicen que somos alegres y combativos. No amigos, no, hemos pasado de la revolución a los porros, punto y aparte».

El movimiento punk en Euskadi al igual que en el Reino Unido es un fenómeno urbano estrechamente ligado a una clase trabajadora que no encuentra solución a problemas como el desempleo, las drogas, la represión policial o la falta de expectativas de futuro. Si bien en un principio las manifestaciones del movimiento punk vasco se limitaron a adoptar y reproducir tanto la estética como la música punk británica y norteamericana, con el tiempo las bandas locales comenzaron a crear un estilo propio que a posteriori sería bautizado por la Izquierda Abertzale como el Rock Radical Vasco. Se trataba de una contracultura pionera en Euskadi que debía hacerse un hueco en un panorama musical y cultural muy definido. Ó Broin (2004: 231) afirma que grupos como RIP, La Polla Records, Hertzainak, Zarama o Kortatu se convirtieron en los pioneros de un sonido alternativo que proporcionó a los jóvenes una banda sonora para su emergente contracultura autogestionada.

Es fundamental no obviar la importancia que paulatinamente fue obteniendo el Rock Radical Vasco en las luchas sociales que se sucedían a lo largo y ancho de la geografía vasca. Ó Broin (2004: 232) recoge mediante una entrevista realizada al cantante de Kortatu, Fermín Muguruza, el siguiente testimonio que da una idea de la relación existente entre el Rock Radical Vasco y los movimientos y luchas sociales del momento; «La escena musical del rock radical estaba muy próxima a las luchas sociales populares de aquellos tiempos. Ya fuera la campaña antinuclear contra la planta de Lemoiz a finales de los setenta o la campaña contra la participación en la OTAN durante los ochenta, la música del rock radical estaba muy presente en las grandes manifestaciones, los festivales y otros eventos políticos». Jakue Pascual (1987: 45) recuerda que durante esa campaña anti-OTAN celebrada en otoño de 1983, el término fue acuñado y presentado en sociedad; "Coincidiendo con la campaña anti-OTAN, se va a comenzar a hablar por primera vez del Rock Radical Vasco, después llegará el boom. Si, esta fecha es importante porque en un acto político se van a concentrar en Muskaria bandas clave como Zarama, Eskorbuto, RIP, Barricada, La Polla Records y Hertzainak. El antropólogo inglés Jeremy McClancy (2007; 31) va más allá y afirma que el concepto Rock Radical Vasco fue acuñado por Herri Batasuna (o Izquierda Abertzale) con una clara intención política. Sugiere además que este concepto fue constituido como una categoría estratégica con la cual dar forma, estimular y politizar un movimiento contracultural musical previo, que no tendría hasta entonces una estructura interna bien definida. Promover el rock radical fue según éste, «un modo para el partido político de organizar y reforzar sus lazos con jóvenes llenos de energía y radicales amantes de la música rock». 
A finales de los ochenta y principios de los noventa se incrementa el surgimiento de nuevas bandas englobadas en el rock radical vasco, que sin embargo mostrarán un compromiso político con la juventud independentista mucho más marcado y militante que sus antecesores; hablamos de grupos como Su ta Gar, EH Sukarra o Latzen entre otros muchos. En general estas bandas pertenecían a un género musical que se alejaba en cierta medida del movimiento punk previo, y que muchos bautizaron como el heavy metal vasco. Los jóvenes cercanos a la Izquierda Abertzale pronto comenzaron a asimilar e identificarse con nuevos géneros musicales que ofrecían un contenido de corte mucho más político y que por primera vez utilizarían el euskera (la lengua nacional) como elemento vehiculante. Ó Broin (2004) afirma que el redescubrimiento del euskera trajo una serie de consecuencias para los músicos y para la generación que les escuchaba. Muchos grupos empezaron a redescubrir la larga tradición de música en euskera anterior al rock radical. Además, al cantar en euskara propiciaban un nuevo empuje del idioma nacional entre los jóvenes y contribuían en la constitución de los nuevos sujetos políticos nacionalistas vascos. El líder de Kortatu, Fermín Muguruza, afirmó en una entrevista realizada por Ó Broin (2004: 234), que «Cada lengua tiene su propia musicalidad y al cantar en vasco estábamos reivindicando nuestra identidad». Jeremy McClancy (2007: 32) incide en el hecho de que la música que engloba el rock radical vasco, es considerada específicamente como vasca por dos razones; la primera porque es producida por vascos y la segunda por que en ocasiones se fusionan el punk, el heavy metal, el reggae o el ska con la música tradicional vasca. En determinadas ocasiones y tras largos periodos de experimentación, estas fusiones y nuevas formas musicales híbridas dieron paso a nuevos estilos y subgéneros musicales específicos del País Vasco. Ekon y su música electro-rockera, por ejemplo, tuvieron una significativa aceptación entre la juventud independentista vasca durante la segunda mitad de la década de los noventa.

Con el paso del tiempo, grupos como Kortatu se disolvieron y sus miembros crearon nuevas bandas musicales como Negu Gorriak (Dub, Rap...) o Anestesia (Trash Metal, Hardcore), que a su vez darían un giro de 180 grados tanto en sus temáticas como en sus estilos musicales. Ó Broin (2004: 235) señala que inexorablemente las influencias externas producirían cambios en la música englobada dentro del Rock Radical Vasco; "A finales de los ochenta muchos de los músicos habían madurado su enfoque de la música y la política. Además de la influencia del punk y el ska, llegaron las del hip-hop, el reggae, el hardcore y otros estilos, entremezclados con un mejor entendimiento de su propia tradición musical».

El famoso grupo de música Hertzainak también vivió una evolución que hizo que su estilo variara, aunque no tan drásticamente como en otros casos. Hoy en día, el cantante de esta banda punk-rock pionera en el Rock Radical Vasco, Gari, continúa cantando, aunque su estilo ha evolucionado hasta convertirse en lo que podríamos calificar como pop-rock alternativo vasco. Es evidente que la mayoría de los grupos que comenzaron su andadura con el Rock Radical Vasco durante los años setenta y ochenta, sufrieron grandes cambios en cuanto a su criterio musical y estética. Tan solo unos pocos fueron fieles a sus inicios más 
transgresores, y ese es el caso de grupos como La Polla Records. Durante la segunda mitad de los noventa hubo un revival de la música punk gracias al grupo navarro Piperrak, que hizo que este género musical se revitaleciera y pusiera de moda de nuevo gracias a canciones como «Odio» (a la Guardia Civil) o «Gora Sartaguda». Los temas y contenidos de carácter político serían evidentes en las letras de esta popular agrupación punk, ofreciendo conciertos y actuaciones en un gran número de eventos organizados por la Izquierda Abertzale. A pesar de que muchos de los grupos englobados en el movimiento punk y el Rock Radical hayan sido asociados directamente al contexto político y cultural vasco, no podemos obviar la gran aceptación que estos tuvieron fuera de las fronteras del País Vasco, tanto en el seno del Estado español como en muchos países de Europa y del continente americano.

Con el paso del tiempo, el rock radical vasco fue fusionándose con la política a pesar de las duras críticas que varios grupos punk como Zikatriz, Eskorbuto o Hertzainak realizaron en un inicio. Los puntos de discordia eran muchos, siendo quizá uno de los más evidentes el relativo al consumo de drogas. Las drogas y sobre todo la heroína, causaron estragos entre la juventud vasca de la época. Una total desinformación sobre ésta, produjo que miles de jóvenes se infectaran con el VIH o que murieran por sobredosis. Ó Broin afirma que el impacto de la heroína fue más profundo en aquellas zonas urbanas donde el rock radical y la disidencia política eran más fuertes. En una entrevista que éste realizó a Fermín Muguruza (2004: 233), el cantante afirmaba que tenía el firme convencimiento de que el consumo de heroína estaba directamente ligado a una estrategia llevada a cabo por los mandos políticos y policiales españoles; «detrás de la distribución de la heroína estaba el Estado Español».

Muchos de los componentes de grupos englobados en el movimiento punk y el rock radical vasco murieron a consecuencia del uso y abuso de la heroína. Todos los miembros del grupo Zikatriz y algunos componentes de Hertzainak y RIP, fallecieron por el consumo de heroína. La postura de Herri Batasuna contraria al consumo de droga era clara y tajante, ya que consideraban que ésta formaba parte de una estrategia creada por el Estado Español que era además llevada a la práctica por la Guardia Civil con la intención de desmovilizar políticamente a la juventud vasca. ETA también tomó sus propias decisiones y varios traficantes de droga fueron asesinados durante los siguientes años.

Con el paso del tiempo varios de los grupos pertenecientes al rock radical vasco adoptaron posturas políticas más definidas, hecho que quedaría constatado en algunas de sus letras. Podríamos destacar entre otros muchos a «Sarri, Sarri», «Hotel Monbar» o «Etxerat» de Kortatu, «Pakean utzi arte», «Kontrola» o «Si Vis Pacem, Parabellum» de Hertzainak y «Lepoan hartu ta segi aurrera» o «Policía no» de RIP. El acercamiento entre algunos de los grupos pioneros del rock radical y la Izquierda Abertzale fue escalonado y se dio durante un proceso que duró varios años. Son muchos los autores que hacen referencia al acuñamiento de la frase «Martxa eta Borroka» para ejemplificar la unión que surgió entre rock radical vasco y los diversos movimientos políticos. Jakue Pascual (1987: 46) afirma que 
«Desde la Izquierda Abertzale teniendo en cuenta la magnitud del fenómeno, se organizan campañas como la de -Martxa eta Borroka- que cuentan básicamente con grupos musicales de estas características». Por otra parte, el antropólogo Jeremy McClancy (2007) señala que Herri Batasuna comenzó a utilizar el eslogan «Martxa eta Borroka» con unos objetivos muy claros. Se intentaba mostrar a los jóvenes que era posible una actitud militante a la vez que se disfrutaba de la fiesta. En palabras de McClancy era una manera de politizar las fiestas tradicionales de modo que en ocasiones conciertos repletos de jóvenes militantes podían terminar en manifestaciones e importantes disturbios en contra de las fuerzas policiales consideradas como ocupantes. Hoy en día, aun podemos observar fenómenos políticos similares como son las kalejiras ${ }^{4}$ a favor de los presos de ETA que se organizan (en ocasiones espontáneamente) en multitud de fiestas municipales a lo largo y ancho de la geografía vasca.

El Rock Radical Vasco también tuvo un rol fundamental en el devenir de diversos acontecimientos socioculturales de carácter nacional/nacionalista. El auge de las radios libres y de los gaztetxes se dieron en parte gracias a los grupos de música englobados dentro del término rock radical vasco. Estos grupos contribuyeron mediante sus mensajes repletos de rebeldía y contracultura, a que miles de jóvenes se echaran a las calles para ocupar edificios vacíos en los que reunirse, dialogar y organizar conciertos. Del mismo modo se gestaron movimientos y asociaciones que derivaron en la creación de radios libres donde la música que tanto los había inspirado pudiera reproducirse para el resto de la sociedad. Los grupos de música punk y rock vascos también se beneficiaron de esta relación, ya que su música pudo llegar a los oídos de miles de jóvenes y consecuentemente muchas de las bandas se hicieron populares incluso más allá de las fronteras del País Vasco. Ó Broin (2004: 238) afirma que «la misma motivación que llevó al surgimiento de los gaztetxes y las radios libres, corre por las venas de tres generaciones de música radical. Al combinar un desafío político a la autoridad, a la hipocresía y a la opresión con la fe en la autoorganización, estos músicos han contribuido a una escena musical plural, vibrante y duradera».

\section{EL PODER PERFORMATIVO DEL PUNK; EL ESTILO}

Para comprender el fenómeno en su totalidad, debemos recordar que el movimiento punk pasó de ser una manifestación cultural y musical británica, a convertirse en una corriente globalizada que posteriormente se relocalizaría adquiriendo una serie características de cada contexto local. Un gran número de incógnitas surgen al pensar en la rápida y exitosa expansión del movimiento punk a lo largo y ancho del planeta: ¿Cómo pudo un fenómeno sociocultural juvenil sin ningún tipo de apoyo institucional expandirse tan exitosamente por todo el mundo?, ¿Por qué un movimiento transgresor y autodenominado como «anti-

\footnotetext{
4 Tipo de pasacalles muy común durante las fiestas municipales que se celebran en el País Vasco, en el que al son de la música se baila, canta e incluso se reivindican elementos de carácter cultural y político.
} 
social», tuvo tan buena aceptación entre los jóvenes de tantos países? Las preguntas y posibles respuestas son innumerables, aunque parece bastante obvio que gran parte del proceso se dio gracias a una serie de acontecimientos y estructuras socioculturales existentes en la época.

Las altas tasas de desempleo en el seno de la clase trabajadora, la falta de expectativas de futuro, las drogas, la desilusión generalizada o la represión política, serían tan solo algunos de los detonantes que facilitaron la rápida y exitosa expansión del fenómeno punk. Sin embargo, hubo dos hechos clave que posibilitaron que este fenómeno fuera tan aceptado entre los jóvenes. Por una parte, se dio una construcción altamente simbólica de una nueva identidad contracultural surgida para oponerse radicalmente a los esquemas sociopolíticos tradicionales que tanta frustración causaban en el seno de la juventud. Por otro lado, no podemos obviar que el movimiento punk contó con elementos altamente performativos y un mensaje transgresor que caló en un importante sector de la población. Además, el Rock Radical Vasco contó con un componente simbólico ligado a la violencia que también resultó ser altamente performativo. La agresiva forma de bailar de los punks o su provocadora apariencia entre otros aspectos, resultaban violentos y amenazadores para las clases más conservadoras de la sociedad. En opinión del antropólogo norteamericano Jeffrey Juris (2008), los grupos radicales englobados en lo que se conoce como el «Black Blok» y que habitualmente llevan a cabo acciones violentas en contra de instituciones y congresos internacionales organizados por los países más poderosos, serían los herederos directos del punk de décadas precedentes. Muchos de los activistas que toman parte en este tipo de estrategias violentas comparten muchos de los rasgos estilísticos, ideológicos y musicales del movimiento punk.

Las performances pueden ser consideradas como representaciones o lenguajes que se rigen mediante códigos verbales o no-verbales de gran simbolismo y de las que se derivan diversas funciones y estrategias socioculturales (Roman, G., 2008). Tanto las expresiones ligüístico-performativas, como las manifestaciones de la violencia performativa (Bordieu, P., 1997) comparten ciertas características en su funcionamiento, desarrollo y reconocimiento ${ }^{5}$ social. A menudo, las performances violentas y/o transgresoras están asociadas a una voluntad de los actores para mostrar su descontento con las estructuras sociopolíticas dominantes El objetivo final de estas acciones performativas estaría por lo tanto, asociado en cierto modo a la función transgresora del movimiento punk expresada a través de su música, su estética y su actitud antisocial. «En el contexto de la acción política, la violencia performativa puede verse como un modo de comunicación a través del cual los activistas intentan hacer efectiva la transformación social mediante una confrontación simbólica basada en la representación de relaciones de antagonismo y la ejecución de imágenes prototípicas de violencia» (Schroder \& Schmidt 2001: 10).

\footnotetext{
${ }^{5}$ Un enunciado o acto performativo debe ser aceptado y reconocido por la comunidad (Bourdieu, P., 1997) en la que éste adquiere valor simbólico y se convierte en una herramienta de representación social, en caso contrario no estaremos hablando de manifestaciones socioculturales o políticas performativas.
} 
Las funciones que se derivan del uso de las performances violentas estarían estrechamente ligadas a expresiones simbólicas de la subalternidad que se manifiestan mediante lenguajes o gramáticas ocultas, pero que resultan totalmente significativas a ojos de sus protagonistas. Cabría pues pensar, que las performances violentas no son meros actos ilógicos como a menudo los cuerpos policiales y representantes de los gobiernos las definen. De estos lenguajes simbólicos y actos performativos subyacen una multitud de elementos como son la identidad, la comunicación o la lucha de clases que por lo general son obviados. Anton Blok (2000) sugiere qué en vez de definir a priori la violencia como un acto irracional, consideremos a ésta como una forma cambiante de interacción y comunicación social desarrollada a lo largo del tiempo de un modo cultural. La etiqueta irracional se derivaría en gran medida de una visión hegemónica occidental que tiende a descontextualizar el fenómeno y divorciarlo de su significación cultural, simbólica y ritual.

La constitución de identidades políticas o culturales es una de las características o consecuencias más evidentes que el uso de la violencia performativa trae consigo (Roman, G., 2015). Los estilos, la música, los lenguajes y códigos lingüísticos (jergas, sociolectos...), así como el compartir una lucha colectiva en contra de un enemigo en común, son elementos focalizadores y canalizadores para la creación o fortalecimiento de una determinada identidad política o cultural. En opinión de Juris (2008), formas específicas de performance violenta pueden asociarse con identidades, estilos y prácticas de oposición particulares. La violencia es utilizada en estos contextos para crear identidad o mostrar oposición/rechazo al enemigo. Jeffrey Juris también afirma que, en el contexto de la protesta política, los activistas utilizan los iconos violentos para comunicar confrontación radical, mientras las fuerzas policiales emplean la actuación violenta, incluyendo uniformes, cascos y escudos militares, para proyectar poder y autoridad.

La creación y difusión de estilos globales a partir de estéticas constituidas en el terreno de lo local (vestimenta, música, peinados, etc.), es un fenómeno que se manifiesta y consolida gracias a los flujos culturales (estilos juveniles...) surgidos con la globalización y la expansión de las nuevas tecnologías (televisión, radio, Internet...). La iconografía y el simbolismo basado en la oposición o confrontación que se manifiesta en los comportamientos y estilos de los grupos enfrentados, son elementos con una gran carga ritual que expresan la existencia de identidades políticas y culturales dualizadas.

En palabras de Feixa y Ferrandiz (2005) las diversas contraculturas juveniles se han caracterizado tradicionalmente por el uso de objetos y estilismos específicos (chaquetas de cuero, pelo rapado, cresta, etc.) que los diferenciaban del resto de grupos. Sin embargo, estos objetos por sí solos y descontextualizados, no serían capaces de crear o formar un determinado estilo. Lo que haría en última instancia que un estilo fuese aceptado e imitado, sería su capacidad para organizar y ligar activamente objetos, con actividades y valores que produjesen y estructurasen una determinada identidad grupal. Hebdige (1979) propone desde una perspectiva semiótica, dos términos mediante los que abordar el con- 
cepto de estilo. Por una parte, alude al concepto de bricolaje o bricoleur acuñado por Leví Strauss en 1972, que sirve para comprender la manera en que objetos y símbolos inconexos son reordenados y recontextualizados para comunicar nuevos significados. Los estilos juveniles producen esta resignificación mediante la inversión de los significados dados, además de combinando en un código diferente o secreto (generado por la misma contracultura) los objetos tomados o prestados de un sistema previo de significados. Esta misma función también se podría lograr mediante la creación de un lenguaje o código lingüístico secreto que los diferenciase de los demás grupos.

Las bandas englobadas en el rock radical vasco y en concreto los grupos punk eran conscientes de este hecho. Por esa razón decidían constituir y reproducir una serie de estilos e identidades que mostraran de un modo performativo su total oposición a los convencionalismos de la sociedad tradicional. A simple vista resultaría difícil diferenciar a un joven punk inglés de la época de otro vasco tan solo por su indumentaria. Presumiblemente se escondía tras los icónicos estilismos punk, una compleja visión del mundo que se fundamentaba en la negación de la «realidad» existente. Desde este movimiento también se criticaban duramente las imitaciones descontextualizadas de personas no pertenecientes al fenómeno punk, que tan solo se interesaban por su llamativo estilismo. La Polla Records compuso en 1984 la canción «Muy Punk» para criticar irónicamente a este tipo de personas.

\author{
Estoy más que aburrido \\ de ver camaleones \\ siempre cambiando de piel con la moda, \\ ¡Mucho idiota! \\ ...Identificarte con nadie, \\ no te va a salvar \\ Vete de aquí \\ que piso mierda. \\ Punky de postal, punk de escaparate. \\ Moda punk en Galerías ¡Muy punk!
}

Hebdige (1979) también propone el término homología para referirse a la simbiosis que se establece entre los artefactos, el estilo y la identidad de grupo. El principio generativo de creación estilística proviene del efecto recíproco entre los artefactos o textos que un grupo usa y los puntos de vista y actividades que estructura (Feixa \& Ferrandiz, 2005). Esto identifica a los miembros de un grupo con objetos particulares que son, o pueden hacerse, homólogos con sus intereses focales. Son varios los elementos utilizados por las contraculturas juveniles con la intención de crear una identidad grupal que los una y los diferencie de los demás: el lenguaje (las culturas juveniles crean habitualmente lenguajes secretos y jergas que los diferencien de sus padres y del resto de grupos juveniles), la música (ésta es utilizada por los jóvenes como un medio de autodefinición o un emblema para marcar la identidad de grupo), la estética (lo que comparten la mayoría de los estilos 
es una voluntad de marcar las diferencias con los adultos y con otros grupos juveniles) o las producciones culturales (producción cultural para consumo interno y externo: grafitis, tatuajes, etc.).

La fusión e imbricación de los elementos descritos anteriormente junto con las condiciones socioculturales de la época, posibilitaron en gran medida el surgimiento y rápida expansión del fenómeno punk por todo el planeta. Centrándonos de nuevo en el caso vasco, deberíamos considerar que las condiciones sociopolíticas y culturales de la época condujeron a que el movimiento punk y otras corrientes musicales fueran englobadas en el denominado rock radical y asociadas a una determinada estrategia política. Las peculiaridades territoriales de Euskadi hicieron que el fenómeno punk global mutara de nuevo a lo local. No obstante, la mayoría de sus características se mantuvieron intactas durante años debido en gran medida a las posturas contrarias a su politización que varias bandas punk mantuvieron. Hablamos de grupos como Hertzainak, Eskorbuto o Zikatriz entre otros.

\section{CONCLUSIONES}

El rock radical vasco fue un término acuñado durante la década de los 80 con una marcada intencionalidad política, que pretendía englobar la adaptación local del movimiento punk británico y otros estilos de la escena musical vasca. Al principio el movimiento punk vasco se limitó a recrear e imitar aquellos estilismos y bandas pioneras procedentes en su mayoría de Gran Bretaña (The Clash o The Sex Pistols entre otros). La corriente Punk, sin embargo, experimentó un proceso de globalización y relocalización que derivó a su vez en el surgimiento de movimientos sociales y culturales de carácter local a lo largo y ancho del planeta. En el caso concreto del País Vasco, el movimiento Punk fue adaptándose gradualmente a la idiosincrasia local mediante la fusión con otros estilos. Aspectos como la lengua, la cultura o la política local pasaron a formar junto con el movimiento punk y otros estilos musicales, parte de un conglomerado que en el año 1983 fue bautizado con el nombre de rock radical vasco. El rock radical derivó en palabras de Ó Broin (2004) en la formación de otros movimientos socioculturales en Euskadi, como son el movimiento antimilitarista, ecologista, feminista y el movimiento okupa.

El movimiento punk fue un fenómeno puramente urbano, y de la urbe hablaban y a la urbe criticaban muchos de los grupos punk englobados en el rock radical vasco. La canción de Kortatu «Mierda de ciudad" es un buen ejemplo de ello. Gran parte de la producción discográfica de estos grupos narraba las historias urbanizadas de jóvenes que hacían frente a problemas derivados del desempleo, las drogas, el amor y el sexo o la violencia. «En el caso del País Vasco resulta patente que el rock radical vasco explica una situación de crisis de la juventud vasca y la carencia de unas alternativas culturales que no tienen cabida en una determinada manera de entender la cultura» (Dávila y Amezaga 2003; 231). 
Aquellos grupos que comenzaron siendo simples proyectos musicales juveniles dieron con el transcurso del tiempo paso a un movimiento reivindicativo y transgresor que en multitud de ocasiones puso en jaque a las instituciones políticas, policiales y judiciales de la época. La fama de estos grupos no se limitó al País Vasco y muchos de ellos gozaron de gran popularidad en el Estado Español y en varios países del continente americano. Probablemente, una de las claves del éxito del movimiento punk residió en su capacidad para criticar a un sistema estéril e indefenso ante la crisis económica y las altas tasas de desempleo. El movimiento logró atraer a miles de jóvenes gracias a la sencillez de su mensaje y a la fuerza de sus críticas contra el sistema.

Algunos de los grupos pioneros del rock radical continúan en el presente formando parte de la esfera musical vasca criticando con sus transgresoras letras aquello que han criticado durante las últimas tres décadas. La Polla Records, Barrikada, Su Ta Gar, Fermín Muguruza o Zarama, son tan solo algunos de los nombres asociados a aquellas bandas que formaron parte del rock radical vasco inicial y que aún continúan dando conciertos a lo largo y ancho de la geografía vasca. No obstante, el camino recorrido hasta nuestros días no ha sido inocuo, ya que muchos de los componentes de los grupos que comenzaron con el fenómeno punk en Euskadi murieron en el camino. Muchos lo hicieron a causa de la heroína, otros tuvieron que dejar la música porque ésta no les proporcionaba el dinero suficiente para poder vivir y otras muchas bandas se disolvieron por razones muy diversas. Por otro lado, el fantasma de la represión política ejercida por el Estado Español y sus cuerpos policiales, siempre estuvo presente desde el comienzo del rock radical vasco. Los componentes de Eskorbuto fueron detenidos en Madrid en 1984 aplicándoseles la «Ley Antiterrorista ${ }^{6}$ y desde entonces han sido multitud los grupos musicales que han tenido que enfrentarse a cargos similares. Tanto Negu Gorriak, como Su ta Gar o S.A. se han enfrentado en algún momento a los tribunales españoles acusados de apología al terrorismo, de calumnias y de otro tipo de presuntos delitos. Sociedad Alkoholika compuso el álbum «Tiempos Oscuros» en el año 2003 para denunciar la persecución político-policial que estaban sufriendo.

El poder performativo y simbólico con que contó el mensaje negacionista del movimiento punk, posibilitó que éste resistiera ante los duros envites de la justicia, los políticos y la sociedad en general durante varias décadas. El movimiento se glocalizó (Robertson, 1995) diluyendo lo local en lo global y viceversa. Las múltiples performances musicales e ideológicas del movimiento punk se recontextualizaron en ciudades y pueblos de todo el mundo mediante una poderosa simbología que aún hoy día continúa estando vigente.

Aunque las culturas y contraculturas juveniles nazcan por lo general en el seno de un determinado contexto económico y sociocultural local, los medios de comunicación y las re-

\footnotetext{
${ }^{6} \mathrm{Al}$ sentirse ignorados por los diversos movimientos sociopolíticos vascos, compusieron la canción «A la mierda el País Vasco» en ese mismo año.
} 
des sociales transnacionales posibilitan habitualmente que jóvenes de lugares distantes se identifique con ellas y las readapten a su propio entorno (Feixa, 2006). Fue probablemente ésta, la clave del éxito del movimiento punk para que una contracultura tan transgresora y relevante pudiera repensar y reconfigurar las relaciones existentes entre miles de jóvenes marginados cultural y socialmente y una sociedad conservadora que nunca logró entenderla.

\section{REFERENCIAS BIBLIOGRÁFICAS}

Blok, A. (2000). The enigma of Senseless Violence, Oxford: Berg.

Bourdieu, P. (1997). Méditations pascaliennes. Paris: Seuil.

Dávila, P. y Amezaga, J. (2003). Juventud, identidad y cultura. Historia de la educación: Revista interuniversitaria. (22-23), 213-231.

Del Amo, Ion Andoni (2016). Party \& Borroka. Jóvenes, músicas y conflictos en Euskal Herria. Tafalla: Txalaparta.

Espinosa, P. y López, E. (1993). Hertzainak. La confesión radical. Vitoria: Aianai.

Feixa, C. (2006). Global Youth? New York: Routledge.

Feixa, C. \& Ferrandiz, F. (2005). Jóvenes sin Tregua. Barcelona: Anthropos.

Hebdige, D. (1979). Subculture. The Meaning of Style. London; Routledge.

Herrera, José Luis. (2009). Filosofía y contracultura. Quaderns de Filosofia i Ciència. (39), 73-82.

Juris, J. (2008). Networking Futures London: Duke University Press.

Lévi-Strauss, C. (1972). The Savage Mind, London: Weidenfeld \& Nicolson.

MacClancy, J. (2007). Expressing Identities in The Basque Arena, Oxford: Sar Press.

Ó Broin, E. (2004). Matxinada: Historia del Movimiento Juvenil Radical Vasco. Tafalla: Txalaparta.

Pascual, J. (1987). El Punk: De England a Euskadi Bailando un Pogo. Inguruak: Revista de Sociología, Vol 3, pp. 41-51. 
El Rock Radical Vasco | Gorka Roman Etxebarrieta

Robertson, R. (1995). Glocalization London: Sage.

Roman, G. (2008), The War of The Symbols: Performative Violence Within the Black Bloc and Kale Borroka, Bilbao: University of Deusto.

Roman, G. (2015). El Deseo Nacional. La gramática del surgimiento de los sujetos políticos. Leioa: UPV/EHU.

Schmidt, E. \& Schröder, I. (2001). Anthropology of Violence and Conflict, New York: Routledge.

Young, R. (1995). Colonial desire: hybridity in theory, culture, and race. London: Routledge. 